\title{
Design of Multi-Sensors Cooperation Control System for Intelligent Building
}

\author{
Qi-Jiao He, Lin Ye \\ School of Power and Energy, Northwestern Polytechnical University, Xi'an 710072, China \\ Email:xazxhqj@163.com
}

How to cite this paper: He, Q.-J. and Ye, L. (2017) Design of Multi-Sensors Cooperation Control System for Intelligent Building. Energy and Power Engineering, 9, 495502 .

https://doi.org/10.4236/epe.2017.94B055

Received: November 27, 2016

Accepted: March 30, 2017

Published: April 6, 2017

\begin{abstract}
This paper presents a design of intelligent building control system based on multi-sensors. In order to achieve comfort, low carbon and energy conservation for buildings. The design uses STC89C52 chip, combined with monitoring data of Pyroelectric infrared microwave dual sensor, temperature sensors and light sensors to control the optical system, the temperature control system and the security system. It helps to achieve low carbon and energy conservation. In addition, the energy-saving effect of a medium-sized multimedia classroom was analyzed. We analyze the feasibility of the system. It is proved that the system is low cost, high yield and easy to operate, with strong engineering application value.
\end{abstract}

\section{Keywords}

Intelligent Building, Multi-Sensors, Control System, STC89C52

\section{Introduction}

In recent years, the global energy shortage and environmental pollution problems have become increasingly serious. The temperature control system technology for buildings cannot update quickly. For example, the increasing problem of "air conditioning diseases [1]" has proved that the old system cannot guarantee the comfort for people. It is urgent to people to take new technology to achieve comfort with emission reduction at the same time. Furthermore, according to the report of the world energy organization [2], China's total energy consumption in 2030 will reach 15 tons standard coal. At present, China's energy consumption of buildings is 3 times the consumption of other countries in the same latitude, and accounts for $30 \%-40 \%$ of the total energy consumption of the country, while in energy consumption of buildings, the energy consumption of air conditioners and ventilating equipment accounts for about 55\%; 
energy consumption of lighting and elevators accounts about $24 \%$. That is to say, each new building means that an increase of energy consumption and emissions, followed by a large number of power consumption, coal consumption [3] [4]. With the development of economy and technology, the technology of "automatic intelligent and energy saving control for buildings" appears and develops well, and this technology can also achieve energy conservation, comfort and practices. The automatically systems with Real-time adjustment and control are bound to become the mainstream of the future architecture.

At present, the building energy conservation is mainly from two aspects: the architectural design and the building intelligent system. The architectural design which is related to energy conservation mainly involves the overall structure of buildings, envelopes and the comfort of indoor environment; and the "intelligent buildings" depends on the advanced networking technology to realize automatic management for buildings, and realize the electricity, lighting, air conditioning, control security, disaster prevention, transportation equipment for buildings, and office automation is a kind of intelligent control management, which helps to build a modern intelligent building [5].

In order to achieve low carbon and energy conservation for buildings, in this paper, the energy-saving control system of new buildings was studied, combined with multi sensors (Pyroelectric infrared microwave dual sensor, temperature sensor, photoresistor) and the embedded control system which intelligently updates "light \& shade optical system, air conditioner \& fan controlling system", "anti-theft \& fire security system", in order to reduce building energy consumption, and improve comfort, social productivity and quality of life and energy conservation.

\section{Design of System}

\subsection{Construction of System}

The energy saving control system consists of eight independent modules: data processing module of Microcontroller, respondent module of pyroelectric infrared microwave dual sensor, indoor and outdoor photometric sampling module, indoor and outdoor temperature sensor and display module, temperature controlling module, lighting controlling module, curtain controlling module, and alarm module. Among these, pyroelectric infrared microwave dual sensors and the photosensitive resistances are besides each lamp, and the temperature sensors are installed in the interior. Three kinds of sensors judge collaboratively, in four operating modes, namely summer normality, winter normality, summer anti-theft, winter anti-theft, and operate respectively for "light \& shade optical system, air conditioner \& fan controlling system", “anti-theft \& fire security system".

\subsection{Design of Light Control System}

As for lighting problem, according to the difference of time, place, person flow, outdoor light intensity, controlling systems use the "preset value" control mode 
to set up light intensity exactly and manage it reasonably, and this helps not only save energy expenses, but also to extend the service life of the lighting equipment.

The pyroelectric infrared microwave dual sensor next to the lamp is used to detect whether there are people in the region. If there is a person in the range of the human body infrared sensor module, it will output high level to the microcontroller I/O port to carry out the corresponding operation. The light intensity of surroundings of lights and curtains are measured by the photoresistor, and after this each light and curtains will carry out their signals [6].

If the Lighting system detects the emergence of a people, the system will start work. If people in the chamber with dark light, it will open lights in this area, and if the light is strong, it will choose not to turn on the lights. Each lamp works independently, in order to save energy as much as possible. If the person leaves the room, the lighting system will automatically close.

The curtain system, whether or not detected people, is open by default. When the outdoor temperature is higher than 30 degree, or the light intensity of a curtain is higher than a certain threshold, the system will automatically close the curtains; until the outdoor light intensity is below the warning level, this helps to pull the curtains to reduce the aging and damage caused by the summer sun.

On this basis, we can use only one button to switch to the projection mode, and also close the corresponding curtains and lamps, in order to create a better projection experience for audiences. In addition, the manual control of the curtain can also be controlled by the physical buttons. The personalized design is very convenient and quick.

\subsection{Design of Temperature Control System}

Temperature control system is aimed primarily to adjust target of air conditioning and fans. Temperature control system module adopt temperature sensor DS18B20, which has a smaller size, higher accuracy, wider applicable voltage, using first-line bus, making a good test in the practical application of temperature effect [7].

Using temperature sensors to detect indoor and outdoor temperatures, combined with indoor and outdoor temperature determines different seasons to adopt different logic. Comparing the sensor signals and system settings, in order to make the appropriate operation of the air conditioning, fan. Meanwhile, the combination of Pyroelectric infrared microwave dual sensor data, namely people distribution inside and the number of people inside the room dynamic partitioning wind direction and speed control, with indoor and outdoor temperature at room temperature instead of a single overall judgment judge. At the same time, the use of fans with air-conditioning work, quickly lower the temperature, so temperature control was maintained at $26^{\circ} \mathrm{C}-27^{\circ} \mathrm{C}$, which is both effectively save resources and improve human comfort, when it is detected that staff leave the room, immediately turn off the fan, delayed 15 minutes turn off air conditioning, choosing the delay to reduce the waste of resources caused by frequent 
switching machine.

\subsection{Design of Security System}

In this modular system, fire prevention function work in real time. Upon detecting a temperature higher than $45^{\circ} \mathrm{C}$, it informs warning center immediately via the communication bus, and the buzzer sounding to alert the floor staff, the maximum extent possible to reduce the loss of fire. Anti-theft mode controls on and off through a physical buttons. In the anti-theft mode turned on, embedded system controls whether an alarm sounds or not. If someone invaded, informs warning center immediately via the communication bus. Communication bus adopts paved telephone line in order to reduce costs.

\section{Design of Hardware \& Software}

\subsection{Design of Hardware}

The system adopts STC89C52 as the core of control which is a low-power, high-performance CMOS8 bit microcontroller with $8 \mathrm{~K}$ code space, $512 \mathrm{~K}$ of data storage space, which can use the serial port to download directly. On a single chip, with dexterous $8 \mathrm{CPU}$ and in-system programmable Flash, so STC89C52 provide highly flexible, ultra-effective solution for many embedded control applications. Figure 1 shows minimum system diagram of Microcontroller (STC89C52) [8].

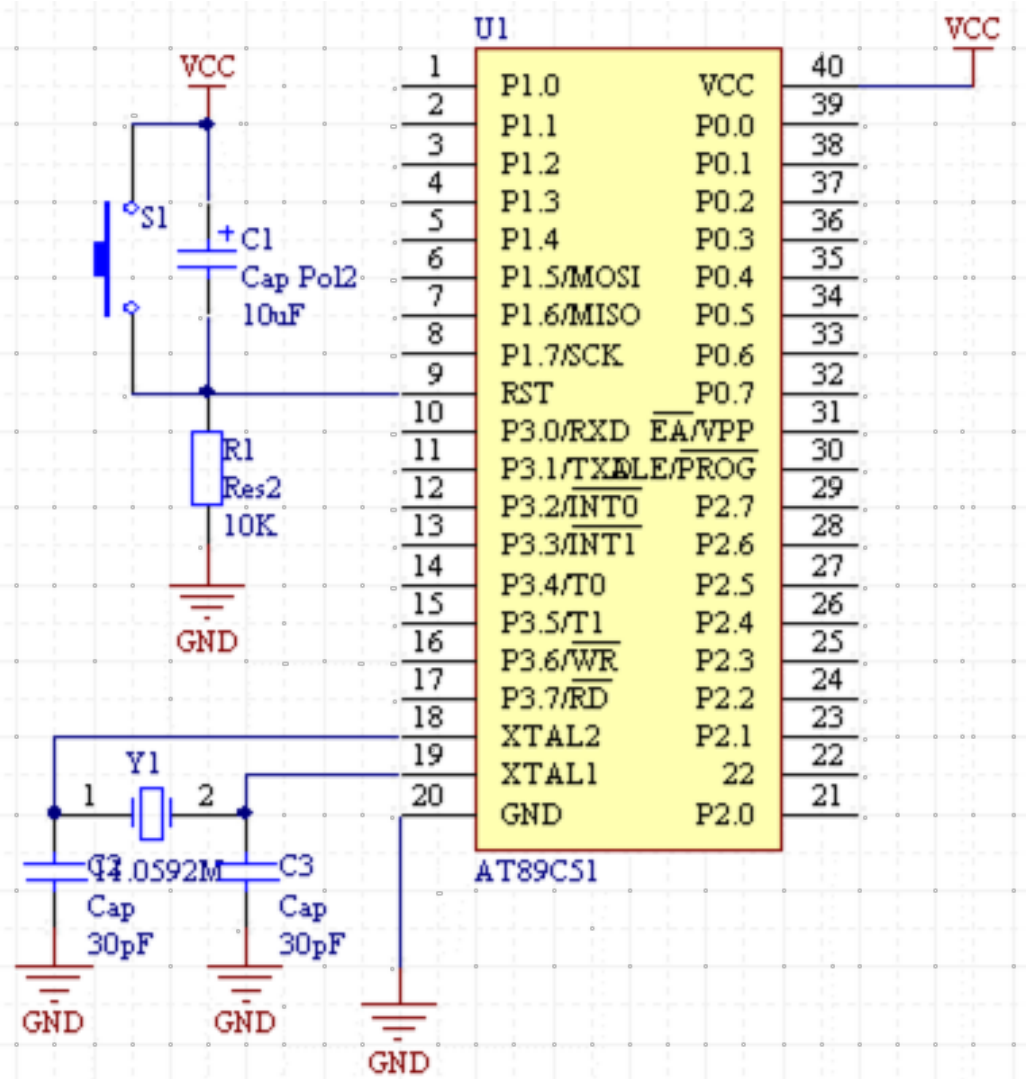

Figure 1. Minimum system diagram of Microcontroller (STC89C52). 
The system adopt hardware Q74 pyroelectric infrared sensor to monitor whether someone appears indoor, adopting DS18B20 temperature sensor to detect indoor and outdoor temperature, and using photoresistor to detect the light intensity indoor. Figure 2 shows a circuit diagram of the system hardware.

\subsection{Design of Software Control System}

The system adopts STC89C52 as the core of control in charge of logic operation of the entire system, so the good or bad software design is the key to whether the stable operation of the system and the ability to achieve design features. In the modular scheme is adopted in the software implementation, the entire software designed by initialization module, interrupt processing module, data display module and output real-time module of four modules, the corresponding module $\mathrm{C}$ programming language program in the microcontroller. After debugging, it expected to achieve control of light control system, temperature control systems and security systems. Figure 3 shows a software system of design flow.

\section{Energy Saving Analysis \& Environmental Impact Assessment}

According to the survey, the vast majority of domestic construction does not use energy-saving measures, and energy consumption is more serious. The intelligent building energy-saving control system is a reasonable design for the current

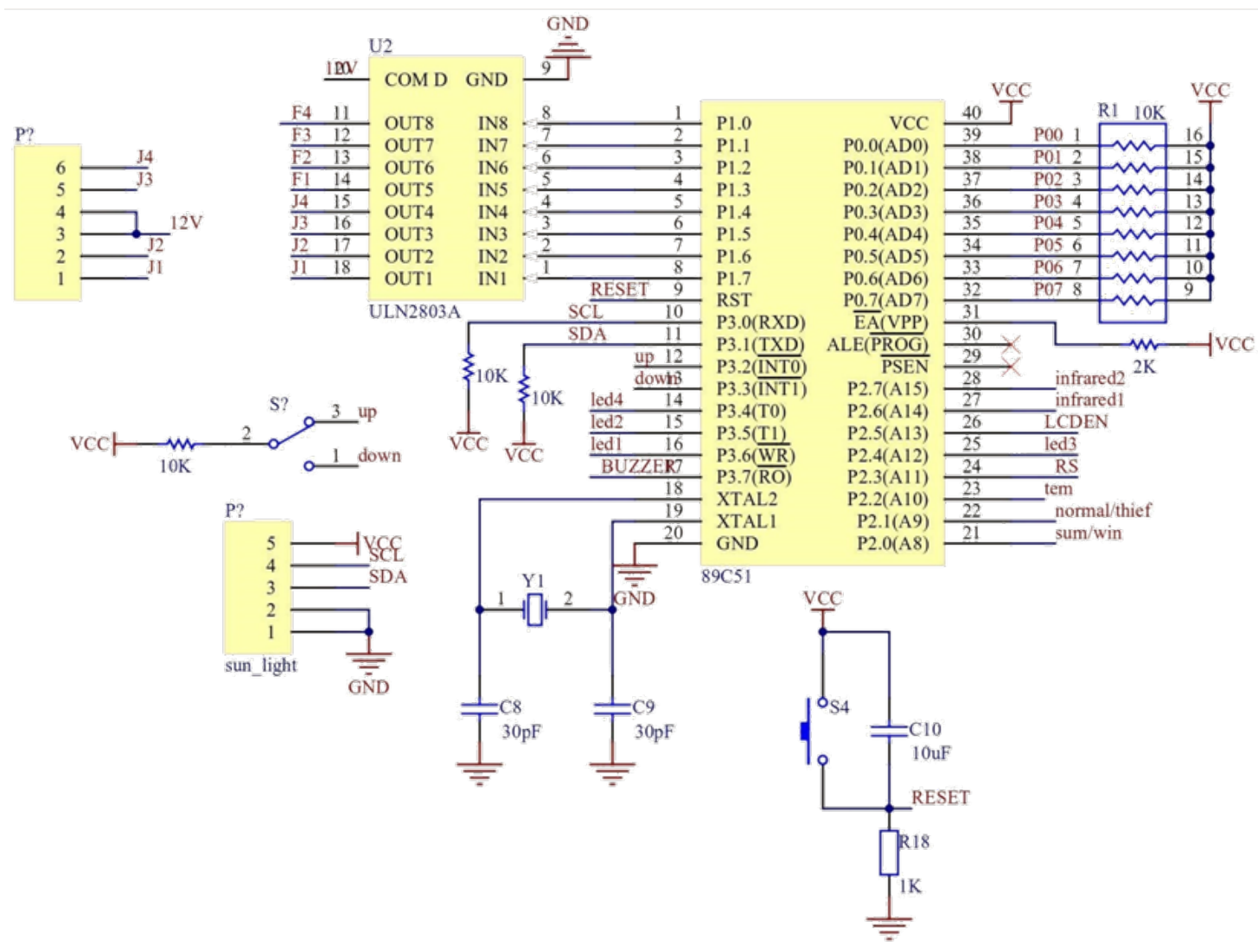

Figure 2. A circuit diagram of the system hardware. 


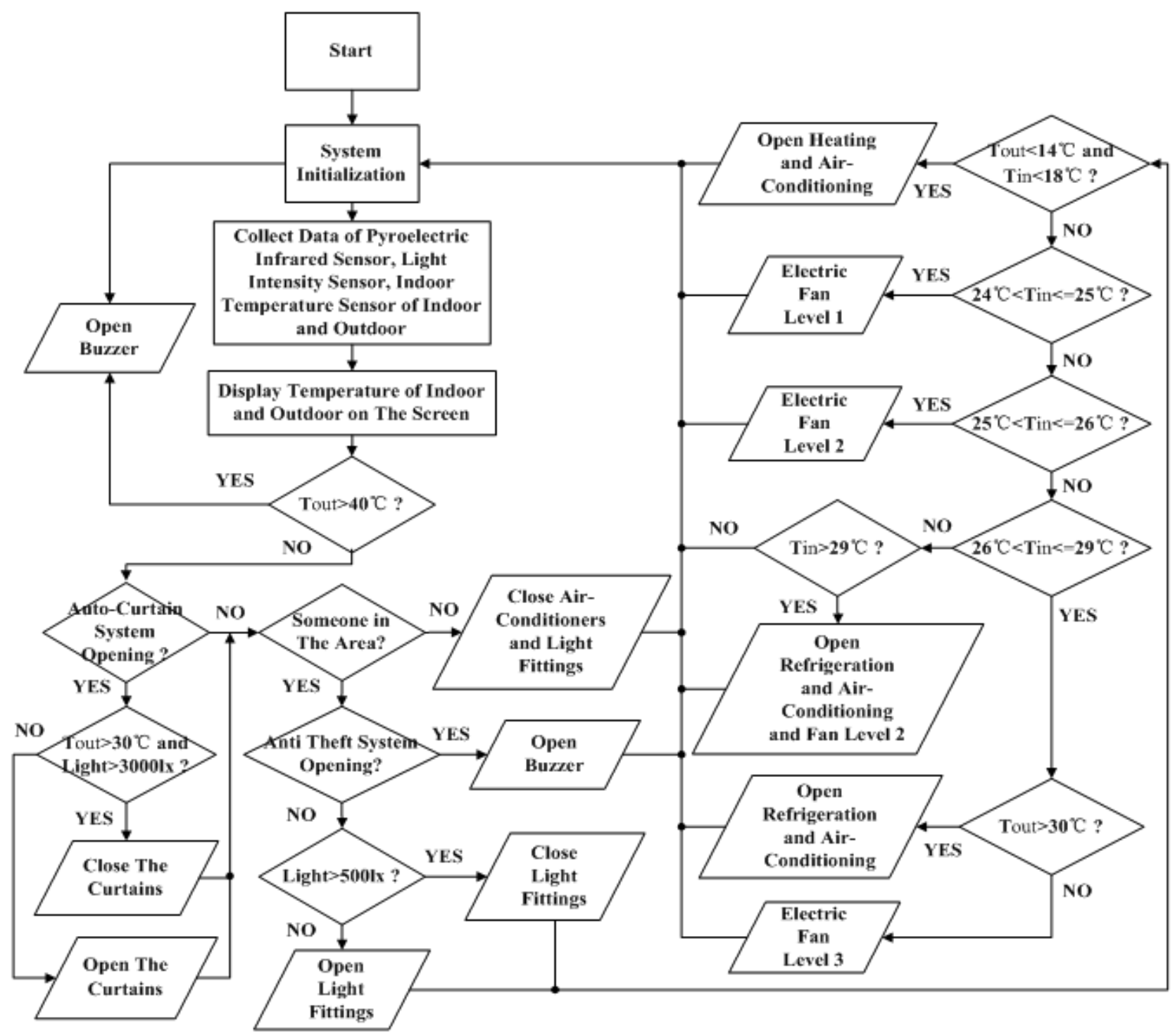

Figure 3. A software system of design flow.

shortage, with a medium-sized multimedia classroom at the University as an example, the system of energy-saving effect as shown in Table 1.

By comparison, the use of the system in each classroom can save $2368.5 \mathrm{kWh}$ of electricity per year, saving 46.3 percent. Equivalent to an annual saving of classroom fired 0.95 ton, reducing $\mathrm{C}$ emissions 0.64 ton, 2.36 ton of $\mathrm{CO}_{2}$ emissions reduction. The system can effectively reduce the amount of waste energy construction sector, on the one hand to achieve the energy saving purpose, on the other hand to improve the life and safety of electrical equipment, and only on the basis of the original circuit was modified without updating existing electrical equipment, low cost, high yield, easy to operate, with high engineering value.

\section{Conclusion}

With the development of society, high energy-consuming products have been 
Table 1. The system of energy-saving effect.

\begin{tabular}{cccc}
\hline & Before use $(\mathrm{kWh})$ & After use $(\mathrm{kWh})$ & Energy savings \\
\hline Lamps & 1555.2 & 920.7 & $40.8 \%$ \\
Air Conditioning & 2808 & 1446.1 & $48.5 \%$ \\
Ceiling Fans & 748.8 & 373.7 & $50.1 \%$ \\
Buzzer & - & 3 & - \\
Total & 5112 & 2743.5 & $46.3 \%$ \\
\hline
\end{tabular}

gradually phased out, and the idea of energy conservation and emission reduction enjoy popular support. Building as an essential place for people's production, living, and 1 earning, optimize the control of energy saving has become the object of study. In this study, the establishment of a multi-sensor based control system, the system using multi- sensor light control system, temperature control system and the security system real-time energy-saving control, and system energy saving test, medium-sized multi-media classrooms each year can save $46.3 \%$, saving $2368.5 \mathrm{kWh}$. At the same time, with the use of modular design, the user can choose according to their needs which several modules to upgrade to fully meet the individual needs. In the building of energy-saving control system can greatly reduce the energy consumption of buildings, and to make the environment more comfortable. And may be building more low-carbon energy, this will bring certain economic benefits.

\section{Acknowledgements}

The authors acknowledge gratefully the financial support from National Undergraduate Training Program for Innovation and Entrepreneurship (Grant No. 201410699051).

\section{References}

[1] Wu, X.P. (2000)The Volume of Outdoor Air, the Way of Air Distribution and Air Conditioning Diseases. Building Energy \& Environment,19.

[2] Organization. (2007) WHO. Housing, Energy and Thermal Comfort: A Review of 10 Countries within the WHO European Region. Copenhagen Who Regional Office for Europe.

[3] Sun, T.Y., Ma, Q., Huang, J. (2015) Energy-saving Control System Design Based on Internet of Things for building. Value Engineering, 15, 61-64

[4] Yao G.Y, Song L. (2014) Design of Library Lighting Energy Saving System Based on Internet of Things. Applied Mechanics \& Materials, 496-500, 1690-1693. https://doi.org/10.4028/www.scientific.net/AMM.496-500.1690

[5] Xu Y. (2008) On the Building Automation System of Intelligent Buildings. Intelligent Building Electrical Technology, 2, 15-18.

[6] Liu, S.Q., Shi, G. L. (2005) Alarm System with Pyroelectric Infrared Sensors. Electronic Design Engineering, 3, 18-20.

[7] Hu, T.M., Qi, J.J. (2008) The design and application of digital thermometer based on DS18B20. Journal of Heilongjiang Institute of Technology, 22, 59-62. 
[8] Wu, J., Hou, W., Zheng, B. (2011) A Temperature Control System Based on STC89C52 MCU. Computer Knowledge and Technology, 7, 902-903.

Submit or recommend next manuscript to SCIRP and we will provide best service for you:

Accepting pre-submission inquiries through Email, Facebook, LinkedIn, Twitter, etc. A wide selection of journals (inclusive of 9 subjects, more than 200 journals) Providing 24-hour high-quality service User-friendly online submission system Fair and swift peer-review system Efficient typesetting and proofreading procedure Display of the result of downloads and visits, as well as the number of cited articles Maximum dissemination of your research work

Submit your manuscript at: http://papersubmission.scirp.org/ Or contact epe@scirp.org 